\title{
VIOLENNCIA E CONTROLE SOCLAL FORMAL: REFLEXÕES SOBRE O SISTEMA PENAL NO ESTADO DEMOCRÁTICO DE DIREITO
}

\author{
VIOLENCE AND FORMAL SOCLAL CONTROL: REFLECTIONS \\ ON THE CRIMINAL SYSTEM IN THE DEMOCRATIC STATE OF

\begin{abstract}
"A construção de um projeto democrático substancial e verdadeiro precisa ser construído no interior dos princípios constitucionais que nos obrigam, uma política de segurança pública cidadã compatível com uma democracia que não é proforma; mas é substancial da vida cotidiana de cada brasileiro e de cada brasileira."
\end{abstract}

Genro (2009, p.23)

Recebido em: 23/03/2018 Aceito em: 25/08/2018

claudioguimaraes858@yahoo.com.br
Resumo: Objetiva-se discorrer sobre os fundamentos do Direito de Punir do Estado e, consequentemente, discorrer sobre os órgãos que exercem na prática tal poder, ou seja, sobre o sistema penal de controle social. Como ponto central da reflexão trazida no presente trabalho, busca-se observar a atuação de tal sistema e sua relação com a população, bem como os reflexos dessa relação sobre o monopólio do jus puniendi. Utilizam-se como premissas os sintomas de insatisfação do corpo social em relação às instituições encarregadas do provimento da justiça penal, buscando-se entender se os constantes ataques ao monopólio do controle social exercido pelo Estado, verificado no quadro de desordem social instalado no país, podem ser legitimados pela ineficácia dos órgãos do sistema penal.

Palavras-chave: Controle social formal. Estado Democrático de Direito. Sistema penal.

Abstract: The purpose of this article is to discuss the grounds of the State's Right to Punish and, consequently, to discuss the organs that exercise such power in practice, that is, on the Criminal System of social control. As the central point of the reflection brought in the present work, seek to observe the performance of such a system and its relationship with the population, as well as the reflections of this relationship on the monopoly of jus puniendi. The symptoms of dissatisfaction of the social body in relation to the institutions responsible for providing criminal justice are used as premises, seeking to understand if the constant attacks on the monopoly of social control exercised by the State, verified in the context of social disorder installed in the country, can be legitimized by the ineffectiveness of the organs of the penal system.

Keywords: Social Formal Control. Democratic State. Criminal System.

\section{INTRODUÇÃO}

\footnotetext{
${ }^{1}$ Universidade Federal do Maranhão - UFMA - São Luís - Maranhão - Brasil

2 Universidade Ceuma - UNICEUMA - São Luís - Maranhão - Brasil
} 
Observando o quadro de desordem social relacionado à prática de atos extremamente violentos praticados em nosso país, refletidos nas cifras apresentadas pelos órgãos competentes ${ }^{2} \mathrm{e}$ denominados de CVLI's - Crimes Violentos Letais Intencionais -, mormente os linchamentos ${ }^{3}$, presume-se que os mesmos podem estar a indicar sintomas de insatisfação da população $0^{4}$ em relação à atuação das Instituições componentes do Sistema Penal (Polícias, Ministério Público, Poder Judiciário e os órgãos da Execução Penal) ${ }^{5}$, fazendo-se, portanto, necessário resgatar, refletir e discutir os fundamentos do monopólio do jus puniendi estatal.

Entendemos, pois, que a prática reiterada desses atos afeta diretamente os fundamentos do exercício de tal poder, exercido pelos órgãos encarregados do controle social formal, desacreditando ainda mais o aparato punitivo nos moldes exigidos por um Estado Democrático de Direito, ainda que, de forma passageira, frise-se, a resposta punitiva privada e imediata à prática criminosa, satisfaça os anseios da sociedade em relação à morosidade e às garantias processuais penais do criminoso observadas durante a persecução penal.

Desta forma é relevante que se faça uma urgente reflexão acerca dos aportes teóricos que fundamentam e conferem legitimidade ao monopólio do Estado na atividade punitiva, com o propósito de reavivar, de reforçar, tanto no meio social como nos órgãos encarregados de tal missão, os argumentos sobre os quais tais bases teóricas repousam.

Para avançar nessa discussão, é necessário observar a atuação das instituições do sistema penal sob a óptica do Estado Democrático de Direito, entendendo, portanto, a importância dos direitos fundamentais em relação ao criminoso e a forma como se dá o seu processamento, mas vislumbrando também a proteção e a tranquilidade da sociedade pela atuação eficiente das Polícias, Ministério Público, Poder Judiciário e os órgãos da Execução Penal, fundamentais à segurança pública.

Observando-se tais argumentos teóricos fundamentais, busca-se entender o impacto que a prática desses atos de autotutela acarreta nas razões de existência do Estado e se, de fato, tem relação com a ineficiência do sistema penal, conforme o discurso de quem os pratica.

Delimitado o objeto de investigação no âmbito da atuação do sistema penal, mais precisamente na (in) eficiência do monopólio do direito de punir e na prática cada vez mais comum dos atos de 'autotutela', é que se pretende enfrentar o problema, fomentando a reflexão e discussão sobre o mesmo. Neste viés não se pode abrir mão da análise jurídico-sociológica moderna, porém, sem esquecer das bases históricas e há muito sedimentadas sobre a origem e criação do Estado.

\footnotetext{
2 Cfr. Waiselfisz (2016) e Cerqueira et al (2017).

3 Segundo o pesquisador Martins (2015), ocorre um linchamento por dia no Brasil. Sobre o tema, imprescindível a leitura de Benevides (1981).

${ }^{4}$ Segundo Waiselfisz (2016), como possível elemento causador dos linchamentos figura o sentimento de impunidade perante crimes hediondos e o enfraquecimento dos órgãos de segurança pública e de justiça no país.

${ }_{5}^{5}$ Andrade (2003) sobre o Sistema Penal, explica que: “... o sistema penal, mecanismo de controle social formal (Legislativo- Lei Penal- Polícia- Ministério Público- Judiciário- Prisão- ciências criminaissistema de segurança pública, etc.) constrói a criminalidade e os criminosos em interação com o controle social informal (família- escola-universidade- mídia- religião- moral- mercado de trabalhohospitais- manicômios), funcionalmente relacionados às estruturas sociais".
} 
Desta feita, traz-se à discussão a atuação das Instituições que compõem o Sistema Penal de controle social, se o mesmo deve sofrer reformas que possibilitem melhor resolver os conflitos sociais e, acima de tudo, se tal forma de controle social é o modo mais eficaz para a redução e o controle da criminalidade.

Por fim, é muito importante que se frise, persegue-se ao longo deste trabalho detectar a gênese do problema enfrentado, para então, como é de praxe para quem comunga das posições da filosofia pragmática, apontar possíveis meios para enfrentamento do problema, mas, acima de tudo, objetivamos contribuir com tão importante debate.

\section{A EVOLUÇÃO DO JUS PUNIENDI: A FUNDAMENTAÇÃO DO DIREITO DE PUNIR}

A figura do jus puniendi surge a partir da criação do Estado 6 e por sua vez a figura deste se confunde com a evolução de convivência entre os sujeitos sociais. Existem teorias que tentam explicar o surgimento do Estado a partir da forma como se deu a associação do homem, sendo mais relevantes a teoria da formação natural e a da formação contratual do Estado 7 .

A teoria da formação natural em síntese, explica que a associação entre as pessoas se dá por um "impulso associativo natural" com o fim de conseguir meios necessários à sua existência. Já a teoria da formação contratual destaca a vontade livre dos homens na criação do Estado com a finalidade de atingir a realização de seus interesses optando por um contrato social ${ }^{8}$.

Hobbes, ao tratar da teoria contratualista do Estado, afirma que todos os sujeitos viviam em "estado de natureza", sendo detentores de liberdade ilimitada. Porém com o advento da propriedade privada, os sujeitos revelam-se maus por natureza vivendo a partir de então em constante vigília, deixando uma sensação de que todos estavam contra todos ${ }^{9}$.

Neste ponto, resolveram os sujeitos, abrir mão de parte de sua liberdade ao Estado Leviatã - em prol da harmonia e paz social. Deste modo, ficou o Estado legitimado a garantir em troca dessa liberdade, as benesses de uma sociedade sem os conflitos antes observados no estado de natureza. (HOBBES, 2014).

Detalhando um pouco mais tal origem, necessário foi retroceder ao ponto no qual o homem é reconhecido como um indivíduo livre por natureza. Entretanto, ao assinar o contrato social abriu mão de parte de sua liberdade em prol da coletividade para que pudesse exercer de forma plena a parcela de autonomia que ainda estava sob sua tutela.

A partir do momento em que os cidadãos assinam tal pacto, autorizam o Estado a zelar pelo seu conforto e segurança, renunciando seus instintos de autodefesa e justiça com as próprias mãos, neste sentido, "Essa passagem do estado de natureza ao estado civil produz no homem uma mudança muito significativa, ao substituir em sua conduta o instinto pela justiça, e dar as suas ações a moralidade que lhes faltava anteriormente". (ROUSSEAU, 2013)

\footnotetext{
${ }^{6}$ Por todos, Heller (1968)

7 Detalhes em Silvestre (2008).

8 Dallari (1998).

${ }^{9} \mathrm{Um}$ aprofundado estudo sobre a Teoria Hobessiana pode ser encontrado em Aurélio (2012).
} 
Importante ressaltar que a lapidação de tal pensamento ocorreu e ainda ocorre, até mesmo pelas exigências contextuais, posto que o próprio Locke ${ }^{10}$, tido por discípulo de Hobbes, acabou por refrear os poderes do Leviatã, limitando a atuação do Estado, exatamente por perceber a importância do reconhecimento dos direitos humanos na relação dos súditos para com o ente estatal, através do co-pacto social.

Ao abrir mão de parcela de sua liberdade, cada cidadão delegou apenas ao Estado o direito de penalizar aqueles que delinquissem contra um indivíduo ou contra toda a sociedade. Fazer "justiça com as próprias mãos" tornaria o cidadão um transgressor semelhante ao delinquente que ao qual desejaria punir.

Em 1764 Beccaria (2014) já advertia:

... a primeira consequência que se tira desses princípios é que apenas as leis podem indicar as penas de cada delito e que o direito de estabelecer leis penais não pode ser senão da pessoa do legislador, que representa toda a sociedade ligada por um contrato social.

Desse modo, visando uma punição mais adequada para aqueles que porventura viessem a atacar outro cidadão ou o Estado, o direito de punir monopolizado trouxe consigo o legislador, que aponta, além das condutas nocivas, a punição correspondente a cada delito praticado.

Neste contexto, a indicação da pena torna-se mais justa, pois além de estar totalmente livre de qualquer sentimentalismo da vítima, é posta de maneira generalizada para qualquer cidadão, que pode realizar um livre exame de consciência para verificar se é mais vantajoso naquele momento fático transgredir o contrato e suportar a respectiva consequência desse ato, ou manter sua conduta de acordo com o que foi consentido no pacto ${ }^{11}$.

A partir do momento em que sedimentada a legitimidade do Estado para disciplinar a sociedade, vez que pertinentes os fundamentos contratualistas, inúmeras foram as teorias que surgiram para tratar sobre os fundamentos aptos a conferirem legitimidade ao Estado no exercício de tal disciplinamento social, neste ponto, destacamos na fase criminológica, as Escolas Clássica e Positivista.

Podemos nos referir à Escola Clássica ${ }^{12}$ como um conjunto de ideias próximas, cujo principal contributo foi a determinação da responsabilidade penal no livre-arbítrio, ou seja, ainda hoje é forte o entendimento de que a punição se fundamenta na ampla liberdade que o homem tem de agir, podendo, deste modo, na qualidade de ser racional, pautar suas ações nos mandamentos legais.

Assim sendo, o delito para tal corrente era a simples violação da norma jurídica, do pacto social que alicerçava o pensamento político liberal; era, pois, um conceito jurídico. Portanto, a pena

\footnotetext{
${ }^{10}$ Vide Locke (1994).

11 Segundo Muñoz Conde (2005), "Para regular a convivência entre os homens, estabelecem-se normas vinculantes que devem ser respeitadas pelas pessoas enquanto membros da comunidade. $O$ acatamento dessas normas é uma condição indispensável para a convivência em sociedade. A ordem jurídica e o Estado não são, por conseguinte, mais que um reflexo ou superestrutura de uma determinada ordem social incapaz, por si mesma, de regular a convivência de um modo organizado e pacífico. Na medida em que a ordem social seja autossuficiente, poderemos prescindir da ordem jurídica e do Estado".

${ }^{12}$ Sobre as Escolas Penais, por todos, Aragão (1977) e Mantovani (2000).
} 
teria por fim dissuadir, desmotivar a prática de delitos, servindo como defesa da sociedade contra o crime.

Em oposição a tais posicionamentos, um outro grupo de pensadores - Escola Positiva passou a defender a ideia de que o delito é anterior à lei, os chamados delitos naturais, ou seja, aqueles comportamentos que iam de encontro à própria consciência social do bom e do ruim, do bem e do mal. A positivação de tais comportamentos na lei era apenas uma questão de segurança jurídica.

Desse modo, havia um rígido determinismo delinquencial, a criminalidade era patológica, o criminoso um ser diferente, doente. A pesquisa etiológica dos crimes, de suas verdadeiras causas, era, portanto, o maior desiderato dos positivistas. Lombroso ${ }^{13}$ passou para a eternidade ao mapear bioantropologicamente os delinquentes que estavam presos.

Em suma, determinadas pessoas já nasciam com propensões criminosas e, deste modo, deveriam ser investigadas e tratadas. A pena tinha um caráter intervencionista e, em seu paroxismo, vigia a máxima: recuperar ou eliminar.

Desta feita, em contraposição ao preconizado pela Escola Clássica erigiu-se a Escola Positiva, que foi completamente adversa ao pensamento do livre arbítrio apregoado por aquela, dirigindo sua atenção para um direito penal do autor sob a perspectiva de descobrir os sintomas ${ }^{14}$ do indivíduo que cometia crimes, não se preocupando em por em foco o ilícito em si, e na qual sobrelevaria a essência de uma "racionalidade classificatória ${ }^{15 "}$ "

Logo, com o fim máximo de defesa e harmonia da sociedade, o Estado ${ }^{16}$ se fundamenta nos benefícios oriundos do contrato social, e busca meios legítimos para o exercício de tal poder no combate à criminalidade pautado nas teorias do crime e da pena, ou seja, na dogmática penal, desta forma o Estado se legitima no combate à criminalidade em razão de os comportamentos delituosos representarem ofensas aos interesses fundamentais dos indivíduos, que atentam contra a existência de toda a sociedade, sendo a lei penal igual para todos, pois a reação frente ao delito é aplicada de forma similar para todos os infratores.

Por todo exposto, fica claro que o dever de persecução e sanção em resposta aos atos de violação da tranquilidade social pertence exclusivamente ao Estado. A legitimidade para utilização de sanções foi adquirida a partir do depósito de liberdades dos sujeitos sociais com o propósito de obter em troca a segurança ${ }^{17}$.

${ }^{13}$ Cfr. Lombroso (2001).

${ }^{14}$ Baratta (2002, p. 38) aclara que: "A reação ao conceito abstrato de indivíduo leva a Escola positiva a afirmar a exigência de uma compreensão do delito que não se prende à tese indemonstrável de uma causação espontânea mediante um ato de livre vontade, mas procura encontrar todo o complexo das causas na totalidade biológica e psicológica do indivíduo, e na totalidade social que determina a vida do indivíduo".

${ }^{15}$ Sobre o assunto, Olmo (1984).

16 Para Clemente (2015), "Todo o Estado dispõe de meios coercitivos para exercer as suas funções: nenhuma autoridade pública dispensa o aparelho coercitivo, próprio ou consignado: o Estado é uma instância autoritativa. O exercício da autoridade pressupõe a faculdade de coagir - nem todo o recurso à força se revela ilegítima e, muito menos, imoral. A força não se opõe à autoridade, nem a liberdade. Em certas circunstancias, só o uso adequado da força garante a vigência das regulações essenciais à vida social.

17 Sobre fundamentação e legitimação do direito de punir, Guimarães (2007). 


\section{SISTEMA PENAL: ÓRGÃOS E ATUAÇÃO}

Ante os graves problemas referentes à criminalidade enfrentados hodiernamente no Brasil, surge no seio da sociedade a sensação de que o controle social formal é ineficaz e, consequentemente, o Direito Penal um instituto falido ${ }^{18}$, que não logram êxito ao exercer suas funções de manter a sociedade organizada e pacífica ${ }^{19}$, conforme o estatuído no "contrato social" no qual os cidadãos acreditavam quando abriram mão de parte de sua liberdade em nome de um bem maior para todos.

Poderíamos sintetizar a questão, fazendo coro ao senso comum, em cuja percepção repousa a ideia de que o sistema formal de controle social não é efetivo nem eficaz, vez que Polícias, Ministério Público, Magistratura e Órgãos da Execução Penal não conseguem atender uma ínfima parte da demanda por segurança pública ${ }^{20}$, que as funções atribuídas às penas não são alcançadas enfim, que o controle está fora de controle.

Nos filiamos ao pensamento oposto, ou seja, no que pertine ao controle social exercido pelo Estado, pensamos que não podemos deixar a cargo do sistema formal de controle da sociedade toda a responsabilidade pela disciplina social ${ }^{21}$, em outras palavras, o déficit de segurança pública hoje detectado no meio social deve ser atribuído à sociedade como um todo e não só ao Estado e seus organismos de controle 22 .

Temos que reconhecer que temos sérios problemas de socialização, não estando a escola, a família, a religião, as relações comunitárias, entre tantas outras instituições pertencentes ao largo espectro do controle social informal, conseguido atender tal demanda, qual seja, a de introjetar nas pessoas o respeito às normas de boa convivência social ${ }^{23}$.

18 Sobre a crise de legitimidade do Direito Penal na sociedade contemporânea, um trabalho atualizado, cfr. Masi (2014).

${ }^{19}$ Sobre os conceitos de ordem, ordem pública e segurança pública, por todos, Araújo Filho (2003).

20 Sobre a responsabilidade na manutenção da segurança e da ordem pública em uma situação de normalidade constitucional, em profundidade, Oliveira (2015), para quem: A ordem pública e a sua manutenção é uma tarefa do Estado movida pelo conjunto dos poderes públicos, ou seja, o poder legislativo, o poder judicial e o poder executivo; seja legislando com o objectivo de manter a ordem pública ou julgando os infractores que desrespeitaram a leis conducentes a assegurar a ordem pública, os vários poderes estão concordantes com o objectivo de manter a ordem pública na sociedade portuguesa. É, no entanto, ao poder executivo, ou seja, ao Governo que compete a responsabilidade pela manutenção da ordem pública, através da delineação de estratégias e modalidades de acção consentâneas com as diferentes problemáticas".

${ }^{21}$ Sobre o assunto, O'Malley (2009).

${ }^{22}$ Segundo Clemente (2015), "O Estado não vive fechado sobre si. Mais que uma questão de Estado, prossecução da segurança é um desafio à sociedade política...Hodiernamente, a demanda de segurança exige soluções à medida dos problemas, baseada na gestão de riscos e das expectativas, seja numa superfície de grandes concentrações humanas - do hipermercado ao estádio de futebol -, seja numa residência isolada...". "Certamente, garantir a segurança é uma responsabilidade do governo de cada Estado, e também da sociedade: a segurança é hoje responsabilidade de todos. E é da responsabilidade de todos, porque a segurança suporta a liberdade cívica e o bem-estar dos concidadãos, bem como a estabilidade do Estado. Na verdade, as sociedades que se fazem responsáveis por sua segurança são sociedades mais livres".

${ }^{23}$ Para aprofundamento no tema, White, Haines, Asquith (2012). 
A partir de tal ponto de vista, ou seja, da divisão de responsabilidades, entendemos que o Estado deve, portanto, ser o promotor da convivência social harmônica através do controle social formal e estimular práticas que estimulem e auxiliem o controle social informal, vez que permanecem válidos os fundamentos que o autorizam para o exercício de tal mister.

Logo, os atos que causarem profundo mal-estar social devem ser investigados e punidos pelos aparelhos estatais com atribuição para tal, em uma perspectiva reativa. Concomitantemente, devem ser desenvolvidas políticas públicas junto às instituições de controle social informal, que evitem a indisciplina social, em uma perspectiva preventiva.

Assim sendo, entendendo ser legítima a atuação do sistema penal, podendo-se afirmar que o controle exercido pelo mesmo é resultado de um processo de evolução. No Brasil, podemos encontrar normas penais nos livros das Ordenações Afonsinas, Manuelinas e Filipinas.

O Livro V das Ordenações Filipinas foi o que melhor apresentou a sistematização das normas penais, porque além de retratar as normas anteriores, apresentou algumas inovações. $\mathrm{O}$ texto do Livro V das Ordenações Filipinas vigorou no período do Brasil Colônia, sendo posteriormente substituído com a outorga da Constituição de 1824, já que, esta última, estabelecia a elaboração de um código criminal que veio em 1830. (TAQUARY, 2008).

No que pertine às instituições componentes de tal sistema de controle penal, existe muita divergência doutrinária. Tomando como base a composição do sistema penal ${ }^{24}$ dos autores Zaffaroni e Pierangeli (2011), afirmam os mesmos que: "o sistema penal é composto pela atividade do legislador, do público, da polícia, dos juízes, promotores e funcionários da execução penal que tem por finalidade o controle social punitivo institucionalizado".

Ainda sobre o sistema penal, Zaffaroni, et. al. (2003), afirma que:

O poder estatal concede às suas instituições funções manifestas que são expressas, declaradas e públicas. [...] um poder orientador que não expresse para que é exercido não pode submeter-se ao juízo de racionalidade. Porém, em geral, essa função manifesta não coincide por completo com o que a instituição realiza na sociedade, ou seja, com suas funções latentes ou reais.

Verifica-se, pois, que na composição de sistema penal trazida pelos autores Zaffaroni e Pierangeli inclui-se o público, sendo esta parte responsável por mobilizar o sistema penal, ou seja, entendem os citados autores que o público tem a faculdade de por em funcionamento a engrenagem do sistema penal, ao tomar a decisão de denunciar ou não a prática de um crime, observando-se uma proporção entre a quantidade de delações e a atividade incriminadora do sistema. (ZAFFARONI; PIERANGELI, 2011)

No que pertine ao modo como deve operar o sistema, em respeito à própria Constituição Federal e seu devido processo legislativo ${ }^{25}$, é pacífica a ideia de que só as leis podem fixar os procedimentos investigatórios e processuais, assim como, definir os crimes e as penas. Tal atividade de fixação e definição pressupõe uma atividade legislativa penal o que torna óbvia a participação do

24 São integrantes do sistema penal o público, o legislativo, a polícia, o judiciário e a execução, porém, na América latina não há uma uniformização do discurso do sistema pelas instituições que o compõe, mas, uma compartimentalização que gera atritos, fragilizando o sistema, que não opera em condições satisfatórias. (ZAFFARONI; PIERANGELI, 2011)

${ }^{25}$ Detalhes sobre o processo legislativo penal e sua relação com a política em Dzimidas (2012). 
Poder Legislativo Federal26, como integrante do sistema penal devendo, entretanto, desenvolver esta atividade de forma legítima ${ }^{27}$. Para ser legítima, essa atividade deve observar o contrato firmado entre os particulares e o Estado. (BECCARIA, 2014)

Neste ponto, devemos observar de que forma atua o legislativo e a forma como se desenvolve a política criminal no Brasil. De plano compreende-se que a lei penal somente pode ser editada pela União.

Ferrajoli ${ }^{28}$ chama a atenção para o entendimento geral que predomina no meio jurídico que advoga ser legítimo, no âmbito interno do direito, aquilo que é válido, ou seja, o direito elaborado conforme as normas que disciplinam a sua produção. Entendemos que para os nossos objetivos tal conceituação se torna insuficiente, sendo necessário que utilizemos também a posição do referido autor relativa à legitimação externa do direito ${ }^{29}$, por assim dizer, é legítimo o direito quando tido como justo, com base em critérios morais, políticos, racionais ou naturais.

Percebe-se, do exposto, ser o binômio legitimador pautado nos fins e objetivos a serem obtidos pelo poder político através do Direito Penal, assim como sua origem, modo e estrutura de exercício, aquele que prevalece na doutrina contemporânea ${ }^{30}$.

Ultrapassados os estágios de provocação para o exercício do controle social levado a efeito pelo público, da elaboração das normas de funcionamento de tal controle elaboradas pelo Poder Legislativo Federal, necessário que se compreenda o funcionamento da disciplina social levada a efeito pelos órgãos que as executam.

$\mathrm{Na}$ perspectiva do conceito de sistema penal proposto, observamos que a preservação da ordem pública e a segurança das pessoas e do patrimônio são promovidas através das polícias (polícia federal; polícia rodoviária federal; polícias civis; polícias militares e corpos de bombeiros militares). (BRASIL, 1988)

São os órgãos policiais, portanto, que asseguram ou tentam assegurar uma convivência pacífica, através do policiamento ostensivo realizado pela Polícia Militar e Guardas Municipais, como também, no caso das Polícias Federal e Civil, são responsáveis pela coleta da prova criminal ${ }^{31}$.

Ainda como membro do sistema penal, a figura do Ministério Público vivencia com a promulgação da Constituição de 1988, um divisor de águas na sua atuação. Neste novo momento,

\footnotetext{
${ }^{26}$ Brasil (1988): Art. 22. Compete privativamente à União legislar sobre: I - direito civil, comercial, penal, processual, eleitoral, agrário, marítimo, aeronáutico, espacial e do trabalho.

27 Ferrajoli (2002a) faz uma séria advertência sobre a legitimidade da justiça penal, aduzindo que "Vinte anos de legislação emergencial, de inflação penal e de progressiva restrição do sistema de garantias produziram a perda de legitimidade da justiça penal, que é apenas contingentemente coberta pela legitimação viciada e, além disso, imprópria, do consenso popular no confronto dos grandes inquéritos. Daí, sobretudo, a necessidade e a urgência de se abrir, finalmente - depois de anos de exceção, de conflitos e tensões políticas, crises institucionais, incompreensões corporativas do mundo da justiça -, um período de reforma idônea refundando em bases racionais e garantistas o direito penal".

${ }^{28}$ Sobre questões afetas à legitimação do Direito Penal, cfr., em uma perspectiva garantista, Ferrajoli (2002b).

${ }^{29} \mathrm{Em}$ maior profundidade, Ferrajoli (2007).

${ }^{30}$ Maiores detalhes em Newburn (2009).

${ }^{31}$ Sobre o funcionamento dos órgãos policiais em um Estado Democrático de Direito, Valente (2015).
} 
coube à instituição, a defesa da sociedade, do interesse público, das instituições democráticas, atuando como defensora dos direitos da cidadania.

Os órgãos que compõem o sistema penal como um todo, e o Ministério Público em particular, devem, no uso de suas atribuições, caso queiram servir de instrumento de implementação de um regime democrático, encontrar novas respostas para a violência que assola a sociedade brasileira $^{32}$.

O Poder Judiciário é dentro do sistema penal, a figura que mediará e resolverá os conflitos, o magistrado deve conceder aos sujeitos investigados e processados bem como à vítima as garantias fundamentais que os amparam, com o fim de propiciar tanto ao acusado quanto à vítima a resolução satisfatória do conflito, observando garantias processuais de ordem constitucional, visto que estas, no âmbito do Estado Democrático de Direito tornaram-se norteadoras na interpretação das normas, inclusive de natureza penal. (CUNHA, et. al. 2010).

No que se refere aos órgãos responsáveis pela execução penal, também integrantes do sistema formal de controle social, mais do que nunca imprescindível que garantam a execução da pena em sintonia com o Estado Democrático de Direito, ou seja que durante o tempo no qual o infrator foi subsumido ao poder do Estado com a perda de sua liberdade, tal perda de liberdade seja a única punição efetivamente imposta dentro da penitenciária.

Em outras palavras, a integridade corporal e psíquica, um ambiente saudável, a ausência de violência, enfim a garantia de respeito à dignidade dos presos, deve ser uma imposição e indispensável à reafirmação dos valores constitucionais vigentes, refletindo o estágio atual da humanização nas relações sociais.

Importante salientar que a lei de execuções penais ${ }^{33}$ e a própria Constituição da República possuem regras que visam aplicar a pena de forma respeitosa e digna ${ }^{34}$.

\footnotetext{
32 Um amplo estudo sobre o Ministério Público brasileiro, pode ser encontrado em Guimarães (2010). ${ }^{33}$ Lei 7.210 de 11 de julho de 1984.

${ }^{34}$ Sobre controle social e pena, Guimarães (2013), assim se posiciona: "Assim sendo, questões de educação, reeducação ou neutralização dos infratores, de intimidação ou reafirmação do valor da norma para os atores sociais, de satisfação para a vítima e/ou seus familiares, não são aptas a legitimar a aplicação das penas, vez que se encontram fora do âmbito do disciplinamento da sociedade pela via do controle social formal. Tais efeitos da pena podem até ser desejados e, em determinadas situações, se concretizarem, entretanto, como consequências possíveis, mas não como fatores legitimantes, até mesmo porque em relação a determinadas teorias há uma clara incongruência semântica entre os termos, vez que não há como conciliar a punição, que é algo que acarreta um mal, com educação ou (res) socialização, que é algo que representa algo positivo. A aplicação da pena se justifica, e só pode se justificar, em razão do fim para o qual foi pensado e criado o controle social formal: exclusivamente a disciplina dos cidadãos como pressuposto de existência da própria sociedade organizada pela via da proteção e manutenção da ordem jurídica. Assim, a educação fica a cargo da rede pública de ensino, a saúde sob responsabilidade dos hospitais públicos e a seguridade social garantida pelo INSS, enquanto a proteção contra atos que atentem contra a própria existência da sociedade organizada fica sob a responsabilidade do Sistema de Controle Social Formal ou Sistema Penal. A partir de tais fundamentos, não há mais como atacar a utilização das penas em razão de não educarem ou reeducarem, de não intimidarem, neutralizarem só parcialmente o infrator, de não ser comprovável que reafirmem o valor da norma, ou de que vítima e/ou familiares não se sentiram compensados com a aplicação da reprimenda penal. $O$ fator de mensuração da legitimidade das penas vai se dar no espaço da segurança dos cidadãos promovida pelo Estado, a saber: se a aplicação das penas está alcançando ou não o objetivo de defesa e manutenção da ordem jurídica pela via do disciplinamento social.
} 
Imprescindível, pois, é que em sede de controle social formal, em tempos de ressuscitamento vigoroso da vingança privada, com execuções sumárias diárias, tal contextualização desfavorável não acabe por oportunizar o aparecimento de soluções mirabolantes e fáceis ${ }^{35}$, sendo necessário que se esteja atento para que os limites históricos, atualmente constitucionalizados como princípios de contenção do poder punitivo, não sejam ultrapassados ${ }^{36}$.

\section{ESTADO DEMOCRÁTICO DE DIREITO, SISTEMA PENAL E SOCIEDADE}

O aumento da violência vem revelando que as políticas de segurança pública ${ }^{37}$, assim como o sistema penal necessitam, urgentemente, de novos aportes teóricos e práticos que auxiliem no resgate de suas credibilidades e diminuam o crescente descrédito da população em relação a tudo que pertine ao controle social formal exercido pelo Estado ${ }^{38}$.

É fato que o aumento no número de linchamentos tem tornado essa prática como algo corriqueiro, natural, mais um componente da dura e injusta realidade social brasileira. Não há dúvidas de que tais atos de barbárie refletem o descrédito da população nos órgãos encarregados pelo controle social formal no Brasil. Ademais, não há como negar, a justiça com as próprias mãos, ou seja, os atos de autotutela são claramente inflamados por setores da imprensa.

O certo é que parece estarmos retrocedendo ao que preconizado por Hobbes (2014) quando da formulação de sua teoria sobre os fundamentos do Estado, que alertava para o perigo da guerra de todos contra todos, para a permanência do Estado de natureza a pautar os relacionamentos intersubjetivos no meio social. Parece que homem está voltando a ser o lobo do homem. No meio científico, vários são os sociólogos, entre outros especialistas, que alertam que a naturalização desse tipo de comportamento pode trazer um risco real à sociedade ${ }^{39}$.

Para piorar um quadro tão desfavorável, o Poder Legislativo com a finalidade de dar algum tipo de resposta à pressão social por mais segurança, como única formar de reverter esse quadro de avanço da criminalidade e da prática de atos violentos de autotutela, vem editando normas

\footnotetext{
${ }^{35}$ Sobre as Teorias que tratam do crime e seu controle, em profundidade, Rock (2007).

${ }^{36}$ Sobre o assunto Ashworth (2009). Dentro de tal perspectiva, Valente (2013) chama a atenção para o fato de que "A constitucionalização da segurança implica considerar a promoção da segurança como uma tarefa fundamental do Estado, prosseguida de forma directa ou indirecta. Há segurança quando a legalidade democrática está salvaguardada, quando os direitos dos cidadãos estão defendidos e garantidos, quando se garante a segurança interna, quando há bem-estar e qualidade de vida do e igualdade real entre os cidadãos, quando se garante a integridade dos princípios do nosso Estado de direito e democrático: de que se destaca a dignidade da pessoa humana, cujo respeito implica o tratamento igual formal, material e em dignidade".

37 Importante destacar que "Ao longo dos séculos foi-se adensando a ideia de que a segurança é um conceito polissêmico e não é algo estático, adaptando-se ao contexto histórico, geográfico e cultural, bem como à conjuntura sócio-política e econômica. Embora historicamente a segurança sempre tenha estado relacionada com a luta pela sobrevivência individual, a sua conceptualização foi prioritariamente associada à vida dos homens em comunidade, à polis e à construção estadual, e na actualidade, inclui o papel de uma diversidade cada vez maior de actores públicos e privados, supranacionais e locais". (ELIAS, 2014). Sobre os desafios da segurança contemporânea, por todos, Fernandes (2014).

${ }^{38}$ Sobre o assunto, cfr. Azevedo (2009)

${ }^{39}$ Cfr. Streit (2017), Martins (1995).
} 
penais exageradamente, abarrotando o sistema penal de novas figuras típicas que pouco ou em nada contribuirão com o fim da citada violência.

A adoção dessa prática é conhecida como direito penal de emergência ${ }^{40}$, onde o legislador, a partir de intensa atividade e visando garantir a ideia de forte atuação infla o ordenamento jurídico com normas sem eficácia ou torna mais duras as normas existentes. O fato é que a experiência tem demonstrado que somente essas medidas não contribuem em nada para a solução da violência.

Ocorre que a atividade legislativa desenfreada e a reforma dos tipos com o fim de tornálos mais duros em nada resolverá o problema quando partimos do entendimento que não é a dureza das penas que fará cessar a criminalidade, mas sim a infalibilidade destas, a certeza da punição. (BECCARIA, 2014)

Portanto, não somente a edição de leis e mais leis resolverá o problema; é necessário que se enfrente a falta de estruturamento e aparelhamento dos órgãos de controle social formal, vez que um fenômeno cada vez mais crescente reflete bem esse problema, qual seja: as pessoas em razão do descrédito em tais instituições não estão mais a buscar seus direitos na seara criminal, na esmagadora maioria das vezes em que são cometidos delitos as vítimas não mais procuram a tutela estatal, não denunciam a prática de crimes.

Tal fenômeno é denominado pela doutrina como cifra oculta da criminalidade ${ }^{41}$, que se trata dos crimes cometidos, que não chegam ao conhecimento das autoridades, fazendo com que não se verifique uma solução para inúmeros casos. Ademais, e para piorar a situação, os casos que chegam até o controle social formal, via de regra pela sua comunicação à autoridade policial, na maioria das vezes, também, acaba sem solução ${ }^{42}$.

Mesmo diante da gravidade do que exposto acima, entendemos que os caminhos a serem trilhados para enfrentamento do problema, passam, necessariamente pelo resgate e fortalecimento dos fundamentos do Estado Democrático de Direito, com ênfase na Constituição Federal.

Fala-se, portanto, em caminhos que não se desviem da legitimidade normativa, leia-se o devido processo legislativo constitucional e da legitimidade social, ou seja, daquilo que a sociedade entenda como o melhor ${ }^{43}$, como o necessário e útil para o apaziguamento social|44.

Neste sentido, deve-se atentar para uma reestruturação e fortalecimento das políticas de segurança, que passam desde o reaparelhamento dos órgãos que compõem o sistema penal até

\footnotetext{
40 Neste sentido Bechara (2008).

${ }^{41}$ A cifra oculta representa a diferença entre a aparência (conhecimento oficial) e a realidade (volume total) da criminalidade convencional, constituída por fatos criminosos não identificados, não denunciados ou não investigados. (SANTOS, 2006)

${ }^{42}$ Sobre a cifra oculta da criminalidade, em profundidade, Baratta (2002), Andrade (2003).

43 Para Valente (2015): "A legitimidade jurídica deve ser a expressão da legitimidade sociológica que fundamenta e justifica a norma penal como uma construção abstrata - fática, valorativa e jurídica -, como reflexo da e na realidade criminal, necessária à tutela mais drástica de bens jurídicos individuais e supra individuais".

${ }^{44}$ Sobre o assunto Garcia-Pablos de Molina (1997), Dias e Andrade (1997).
} 
um permanente diálogo ${ }^{45}$ entre os setores civis e profissionais envolvidos, com o intuito de que se leve a efeito a discussão de propostas, principalmente aquelas que já se mostraram eficientes em outros países, e que possam atender as necessidades de uma população insegura sem, contudo, como seguidamente temos insistido, esquecer as garantias fundamentais que devem prevalecer em um Estado do Direito ${ }^{46}$.

Necessário, também, que se tragam os especialistas no assunto para o debate, ou seja a academia brasileira deve ser ouvida sobre a formulação de políticas criminais que possam informar o legislador, de forma aprofundada, sobre as questões sociológicas que envolvam o controle social formal e informal ${ }^{47}$. Defendemos a ideia de que essa é a seara mais propícia para que através da análise crítica de toda a atual situação da segurança pública no Brasil, possam ser disponibilizados subsídios para a correção de políticas equivocadas, concepção de novas estratégias, superação de velhos paradigmas e, em suma, que sejam fortalecidos os novos referenciais para trato do problema que já tenham se mostrados aptos por se configurarem como experiências bem-sucedidas ${ }^{48}$.

Em outro viés, importante que se aprofunde a discussão sobre a liberdade de imprensa, resvalando para o âmbito da imprensa responsável, vez que a espetacularização da violência em nada contribui para a sedimentação da democracia, para a concretização dos fundamentos que dão vida ao monopólio do direito de punir do Estado e, portanto, à própria subsistência da sociedade ${ }^{49}$.

Com o aumento da criminalidade, sua ampla divulgação nas mídias ${ }^{50} \mathrm{e}$, principalmente, a busca da audiência a qualquer preço, cenas de violência sem a devida contextualização passaram a fazer parte do dia a dia da população, trivializa-se 0 ataque às normas e instituições que dão sustentação à existência do Estado, enfraquece-se qualquer tentativa de implantação de políticas de segurança pública ${ }^{51}$.

O crime organizado, as facções criminosas e, consequentemente, delinquentes de altíssima periculosidade tem ganhado um espaço exacerbado nos meios de comunicação, elevandose estes últimos ao status de celebridades. Parece mesmo que existe uma campanha em prol da inversão da verdade, ou seja, parte da imprensa parece querer fazer crer que o crime compensa. Tudo isso contribui para o aprofundamento da crise de legitimidade que hoje atravessa o sistema formal de controle social.

\footnotetext{
45 A primeira CONSEG foi um espaço de diálogo na busca pela efetivação dos direitos humanos, anseios da sociedade e necessidades dos profissionais envolvidos com a segurança pública.

${ }^{46}$ Cfr. reportagem da BBC (2017).

47 Sobre o assunto, por todos, Ferrajoli (1997).

48 Para maior aprofundamento no tema, Sento-Sé (2005).

49 Sobre crime e mídia, Katz (2009).

50 Detalhes em Dallari (2006)

51 Como conceito de Política de Segurança Pública, adotamos o de Caldeira (1998), que assim se posiciona: "Política de Segurança Pública consiste na escolha, pela autoridade estatal, dos bens e direitos que serão protegidos jurídica e penalmente, bem como dos recursos e métodos que serão usados para efetivar esta tutela. Trata-se de uma das políticas governamentais e, como tal, está condicionada por fatores políticos, eleitorais, orçamentários, administrativos, ideológicos e outros, como qualquer processo decisório governamental. A política de segurança pública, dado o seu intenso monitoramento pelos meios de comunicação de massa, é ainda condicionada pelo tratamento que lhe dá a mídia. Através de suas omissões, ênfases ou deturpações, os meios de comunicação de massa têm papel importante na construção da percepção dos fatos pelo receptor das notícias".
} 
Em relação aos poderes públicos, percebe-se muito claramente que as esferas federal, estadual e municipal não têm trabalhado conjuntamente, em sintonia. As respostas dadas à crescente violência são insuficientes, menos incisivas e corajosas do que a gravidade do problema requer. Imprescindível que o Governo Federal, Estados e Municípios planejem e executem ações multissetoriais bem coordenadas ${ }^{52}$, com a elaboração de políticas públicas voltadas especificamente para a segurança, focando, principalmente, no âmbito da prevenção e, portanto, levando a efeito ações que estejam fora da perspectiva repressiva/punitiva/reativa ${ }^{53}$.

No que pertine especificamente às instituições que integram o sistema formal de controle social, temos que observar a atuação das polícias, e neste ponto destacamos a insuficiência dos homens a serviço da manutenção da ordem. A atuação preventiva ${ }^{54}$ desses profissionais em muito contribui para a diminuição da criminalidade ${ }^{55}$.

Neste ponto fica claro que o investimento no material humano e a nas ferramentas de trabalho dos policiais é uma possível solução efetiva contra a crescente criminalidade. Evidente que aqui destacamos que a atividade do policial deve observar os limites da dignidade da pessoa humana ${ }^{56}$.

Ocorre que, hodiernamente, a relação entre as instituições policiais brasileiras e a população é de descrédito. Dentre as situações que causam essa insegurança, como já dito, está na insatisfação quanto a capacidade de resolução de conflitos. (SILVA; TASCHETTO, 2008)

Uma possível solução seria uma mudança na formação profissional dos policiais. Não temos dúvida que o aprimoramento da democracia e da cidadania e, portanto, das relações sociais em todos os níveis, passa, inexoravelmente, pelo aprimoramento individual de cada membro do corpo social, desta forma, novas experiências de mudanças na formação e atualização de policiais poderiam ser potencializadas e aprimoradas, o que contribuiria para uma melhor prestação de serviços desses profissionais e, consequentemente, para a mudança da imagem da polícia ante a população ${ }^{57}$.

52 Vários países já estão desenvolvendo políticas de recuperação do espaço público degradado como forma de combate à criminalidade. Maiores detalhes sobre tal temática, cfr. Weber e Crane (2015).

53 Sobre o assunto, detalhadamente, Soares (2005) e Guimarães e Pereira (2014).

${ }^{54} \mathrm{De}$ acordo com a Secretaria de defesa social de Pernambuco o aumento do efetivo policial nas ruas e novos veículos para a segurança pública teriam relação com a redução dos índices de assassinatos no Estado (SANTIN 2001).

${ }^{55}$ Sobre o papel das polícias na manutenção da ordem pública, por todos, Oliveira (2015)

56 Visão aprofundada em Silva e Taschetto (2008).

57 Segundo Soares (2003) "Na transição democrática, todas as instituições públicas e seus procedimentos passaram por uma revisão e reajuste ao novo momento. Uma destas instituições, entretanto, acabou esquecida: a polícia. Conservadores, liberais e progressistas debateram o destino de cada órgão público, discutiram propostas antagônicas e disputaram a liderança de cada processo de reforma. No entanto, com raríssimas exceções individuais, deixaram de apresentar à opinião pública projetos que adequassem a polícia à democracia então estabelecida. Essa omissão condenou a polícia 1 à reprodução inercial de seus hábitos atávicos: a violência arbitrária contra excluídos (particularmente pobres e negros), a tortura, a chantagem, a extorsão, a humilhação cotidiana e a ineficiência no combate ao crime, sobretudo se os criminosos pertencem a altos escalões. Claro está que sempre houve milhares de policiais honestos, corretos, dignos, que tratam todos os cidadãos com respeito e apresentam-se como profissionais de grande competência. Mas as instituições policiais, em seu conjunto e com raras exceções regionais, funcionaram e continuam a funcionar como se estivéssemos em uma ditadura ou como se vivêssemos sob um regime de apartheid social". 
Neste sentido, o ensino policial deve estimular desde o início a importância de uma polícia humanizada e cidadã ${ }^{58}$. Destaca-se a necessidade de qualificação em níveis de pósgraduação dos responsáveis pela formação de novos policiais (LUIZ, 2008).

Em outra análise, no que pertine ao policial, as condições de trabalho atuais são favoráveis à corrupção deste profissional. Com baixos salários, ameaça constante a sua integridade física e a desvalorização da profissão, entre outros problemas inclusive de ordem psíquica, estão a afetar a forma como o policial vê sua profissão. ${ }^{59}$

O enfrentamento de tal problema está intimamente ligado à questão do aprimoramento da performance policial. Isso se traduziria na necessidade de que se combata e reduza a impunidade, sendo pressuposto de tal meta a própria redução da corrupção policial. O resultado de políticas exitosas em tais desideratos acabaria por transformar as nossas polícias - assim como os policiais em instituições menos violentas e corruptas, mais respeitosas dos direitos humanos, mais inteligentes e eficientes, mais aptas a agir preventivamente, mais confiáveis e, portanto, mais legítimas e capazes de valorizar seus profissionais ${ }^{60}$. (SOARES, 2003).

O Ministério Público ocupa lugar de destaque para o cumprimento do programado pela lei penal, tendo, por isso mesmo, que ser co-responsabilizado pelas consequências advindas da violência que permeia todos os conflitos sociais encaminhados para solução pela justiça penal. Ao atuarem pautados pelo modelo clássico de intervenção, pautado exclusivamente na reação representada pela ação penal, os Promotores e Procuradores acabam por colaborar muito pouco para a redução da violência, posto que ao exercerem suas atribuições reduzindo o conceito de violência ao cometimento de delitos violentos, ajudam a escamotear toda a violência estrutural e suas nefastas consequências produzidas pelo poder constituído.

Entendemos, assim, que o papel que deve ser desenvolvido pelo Ministério Público no combate ao aumento da criminalidade deva se dar, prioritariamente, fora do âmbito do sistema penal. Deve, pois, a instituição ministerial atuar proativamente para efetivação dos direitos e garantias previstos constitucionalmente e que tenham como prioridade a erradicação da pobreza extrema e, consequentemente, a erradicação da injustiça social.

Ainda na esfera do sistema penal, com foco eminentemente voltado para os crimes que efetivamente estão a impedir os objetivos da República, deve o Ministério Público, de modo amplo, abarcar todos os assuntos ligados ao combate de crimes econômicos, financeiros e de corrupção, participando ativamente das fases investigatória e persecutória.

Deve elaborar e discutir políticas de prevenção como prioritárias às políticas de segurança pública, diminuindo a distância e aprofundando o diálogo com os órgãos políticos, tanto o legislativo como o executivo, para o desenvolvimento de tal mister.

58 Sobre as relações da cidadania com a atividade policial, por todos, Clemente (2015).

59 Um modelo bem-sucedido de redução da criminalidade pode ser encontrado nos EUA, especialmente em Nova York, com uma política que privilegia o aumento do efetivo das policias, a exclusão de membros corruptos, bons salários e boas condições de trabalho - policiamento massivo nas chamadas em áreas problemáticas, blitz constantes e intensivas, alto índice de certeza de castigos, entre outras medidas, inclusive, de reurbanização da cidade. Entre tantos outros aportes teóricos que levaram a adoção de tais medidas, um dos mais conhecidos é a teoria das janelas quebradas, que pode ser acessado na íntegra em Wilson e Kelling (2009).

60 Sobre o tema, imprescindível a leitura de Lima et al. (2016). 
Residualmente, em relação à delinquência comum, quando da ocorrência de delitos, deve o Ministério Público ter conhecimento imediato da ocorrência, para que possa participar e interferir no trabalho de investigação criminal, o que, por certo, permitirá uma atuação mais fundamentada na instrução judicial e na efetiva realização da prestação jurisdicional.

Em relação à execução da pena, deve o órgão ministerial garantir a preservação dos direitos humanos, pilar fundamental de um regime republicano e democrático, sempre pautado pela máxima segundo a qual o único direito perdido pelo condenado é o da liberdade. Em tal seara deve estar atento à reparação dos danos provocados pelos crimes, com o objetivo de melhor proteger a vítima.

No que pertine ao Poder Judiciário, que tem sido alvo de contundentes críticas, com mais ênfase na questão da morosidade, deve este buscar um melhor aparelhamento com fins de modernização que lhe permitam melhor desempenho na prestação jurisdicional.

Não devem os magistrados abrir mão do princípio da igualdade perante a lei, o que se traduz por um tratamento isonômico de todos os acusados, respeitando o que proposto em tal área pela Constituição Federal que é, frise-se, garantista. Assim sendo, as decisões judiciais devem garantir ao réu os direitos e garantias inerentes a um Estado Democrático e de Direito, não podendo qualquer convicção pessoal estar acima da lei.

Devem-se estar atentos para que as aplicações dessas regras não sejam desvirtuadas em razão das tensões oriundas dos altos níveis de violência, deixando de lado prerrogativas importantes quando da atuação do Estado na esfera do controle social formal. É neste ponto que o Poder Judiciário deve atuar como verdadeiro dique de contenção dos excessos punitivos - tanto em nível de investigação, como de persecução processual e execução da pena -, exercendo suas funções de modo racional, imparcial, e, sobretudo, com razoabilidade e proporcionalidade ${ }^{61}$.

Sintetizando, devem os Magistrados buscar a eficiência da prestação jurisdicional, traduzida em uma maior celeridade nos feitos, como forma de combater a sensação de impunidade que hoje prepondera na opinião pública, sem, contudo, antagonizar eficientismo jurisdicional com direitos e garantias constitucionalmente assegurados.

O fato é que os operadores do Direito, mormente aqueles que integram o sistema formal de controle social, nunca devem perder de vista que as definições dos limites legais na esfera da investigação, processamento e punição daqueles que cometem infrações penais, estão a cargo do legislador, sob pena de, não respeitando tal princípio básico, colocarem em risco a própria vigência do Estado de Direito.

Como últimos integrantes do Sistema de Controle Social Formal, figuram os órgãos encarregados da execução penal, aqueles que efetivamente lidam com o dia a dia do sistema penitenciário.

Sabe-se que o Brasil é o quarto país que mais encarcera no mundo e, mesmo assim, convive com taxas de criminalidade muito altas, segundo o Anuário Brasileiro de Segurança Pública (BRASIL, 2016)

\footnotetext{
${ }^{61}$ Sobre o tema, cfr. Fisher (2013).
} 
Dados extraídos do relatório da CPI do Sistema Penitenciário Nacional revelam graves problemas na maioria das unidades que compõem o sistema carcerário, alertando para o fato de que não são minimamente observadas as determinações contidas na Lei de Execução Penal e, logicamente, as normas constitucionais que informam tal diploma legal, concluindo, outrossim, que o Sistema Penitenciário Nacional necessita urgentemente de uma maior atenção das autoridades competentes, para que sejam levadas a efeito profundas reformas estruturais e gerenciais ${ }^{62}$. (BRASIL, 2015)

Pensamos que o fio condutor para todas as reformas necessárias no Sistema Penitenciário Nacional, e que, reconheçamos, não são simples nem poucas, devam ser fundamentadas em uma palavra: respeito.

Respeito pela dignidade do ser humano.

Violência não se combate com violência, ademais, existe todo um aparato teórico que deu vida e hoje dá sustentação à existência do Estado, com fins de promoção das melhores possibilidades de convivência em sociedade, indicando o caminho da democracia, da cidadania ativa e do respeito aos direitos e garantias fundamentais do ser humano, como o caminho a ser percorrido para o alcance tal desiderato.

É neste sentido que concluímos o presente trabalho, alertando que o problema da violência urbana desenfreada e a os autos índices de casos de prática de autotutela está relacionado à políticas criminais mal planejadas que trazem a reboque uma prática de segurança pública contrária às necessidades sociais.

Assim sendo, defendemos a ideia, segundo a qual, o que de fato a sociedade almeja é que as instituições que compõem o sistema de controle social formal do Estado, enfrentem a violência social, com foco especial na criminalidade, desenvolvendo políticas públicas inclusivas e preventivas ${ }^{63}$, paralelamente a políticas repressivas, conforme acima exposto, com a finalidade de apaziguamento social, sem que haja necessidade da própria população chegar a atos extremos de autotutela.

62 Interessado em conhecer a eficácia do sistema penitenciário, o Conselho Nacional de Justiça (CNJ) solicitou do Ipea uma pesquisa sobre reincidência criminal no Brasil. O objetivo da pesquisa era a coleta e apresentação de dados que permitissem determinar a taxa de reincidência criminal, com o intuito de aprimorar o sistema de justiça penal e informar o planejamento do Poder Judiciário, buscando tornar a execução penal mais eficaz, eficiente e efetiva. (IPEA, 2015)

$63 \mathrm{Um}$ aprofundado estudo sobre políticas públicas pode ser encontrado em Moran, Rein e Goodin (2015). Sobre políticas públicas e prevenção criminal, especificamente, Welsh e Farrington (2014, tradução livre), para quem "A prevenção criminal tem tido diferentes significados para pessoas muito diferentes. Políticas e programas desenvolvidos para prevenção criminal podem incluir desde prisões para combater gangs, acordos judiciais para evitar penas privativas de liberdade, até mesmo, numa perspectiva extrema, a pena de morte. Tais medidas seriam mais corretamente conceituadas como controle do crime ou repressão criminal. Mais frequentemente, entretanto, a prevenção criminal se refere a atos que busquem combater o crime antes que o mesmo aconteça. Ambas as formas apresentadas têm em comum o fato de pretenderem evitar a prática delitiva futura, mas se distinguem pela prevenção criminal não repressiva ocorrer fora do âmbito do sistema formal de justiça". 


\section{CONCLUSÃO}

Com base em todo o exposto nos limites do presente trabalho, entendemos que as teorias que dão sustentação à existência do Estado são totalmente pertinentes às necessidades sociais, devendo ser constantemente resgatadas e trazidas para o contexto de qualquer discussão que queira se travar em termos de controle social - formal e informal.

Entendemos, outrossim, que nessa discussão sobre controle social, o que deve imperar hoje, como acabamos de colocar acima, não é a temática da necessidade ou não da intervenção do Estado na disciplina da sociedade e, sim, como mediar a atuação do sistema penal para respeite as garantias fundamentais individuais sem perder de vista as garantias fundamentais coletivas, os interesses comuns por segurança e paz.

Defendemos ferrenhamente, pois, esta ideia, vez que para combater o descrédito que hoje permeia as relações entre o Estado, na sua função principal - razão mesmo de sua existência -, que é o da disciplina e manutenção da ordem social e jurídica, necessário que se ouça os anseios sociais, fonte de toda a legitimação da atuação do Estado, leve-se a efeito a filtragem constitucional de tais aspirações do povo, para que direitos e garantias sejam preservados, e busque-se meios pela via legislativa, executiva e judicial para concretizar tais aspirações.

Enfim, para que os grotescos atos de autotutela não se trivializem mais e mais no imaginário da população, refletindo a descrença na capacidade de gestão disciplinar do Estado, devem as instituições pertencentes ao sistema penal, observarem sim, as garantias do investigado, réu e condenado, porém, deve fazê-lo sem deixar de atender às necessidades da coletividade, que necessita de segurança e paz.

Em relação aos órgãos que compõem o sistema penal de controle social formal, apontamos que em todas as suas esferas, como é normal, vez que tudo sempre poderá ser melhorado, existem, em maior ou menor medida, falhas.

Tais falhas se refletem tanto no aspecto material, de aparelhamento destes órgãos, como também no aspecto formal, de atuação. Não restam dúvidas, portanto, que Polícias, Ministério Público, Judiciário e órgãos afetos à execução penal, que são os componentes executivos de tal sistema, necessitam de investimentos para reaparelhamento material e de reformas no âmbito de suas próprias percepções, enquanto agentes garantidores da harmonia, paz social, cidadania, em suma, garantidores da existência de um Estado Democrático e de Direito.

Ao Poder Legislativo cabe o importante papel de concretizar as aspirações sociais em termos de legislação, estando sempre atento para que as leis que venham a ser produzidas, principalmente em tempos de tensão social como estamos a atravessar agora, não acabem por representar retrocessos em termos dos duros avanços conquistados pela humanidade em torno de seus direitos e garantias inalienáveis.

Em suma, acreditamos que a (des) crença nas instituições do sistema penal e o abismo que separa a população de tal sistema estão diretamente relacionados às insatisfações causadas pelas respostas que os órgãos que o compõem estão a dar aos anseios sociais por mais segurança e menos impunidade, o que, em seu paroxismo, se reflete nos atos de autotutela.

Revista do Direito [ISSN 1982-9957]. Santa Cruz do Sul, v. 1, n. 57, p. 138-159, jan/abr. 2019. https://online.unisc.br/seer/index.php/direito/index 
Cabe a sociedade, portanto, pela via da democracia, exercendo sua cidadania ativa pelo meio de boas escolhas representativas, corrigir os rumos destas assimetrias, sem contudo, em nenhuma hipótese, postular a população tomar o lugar do Estado no exercício do jus puniendi, o que com toda a certeza, tem e sempre terá um efeito completamente inverso ao pretendido, ou seja, com a autotutela levada a efeito, mais distante nos encontramos da segurança, paz e harmonia social.

\section{REFERÊNCIAS}

ANDRADE, Vera Regina Pereira de. A llusão de Segurança Jurídica: do controle da violência à violência do controle penal. 2. ed. Porto Alegre: Livraria do Advogado, 2003. 336 p.

ARAGÃO, Antônio Moniz Sodré de. As Três Escolas Penais: Clássica, Antropológica e Crítica. 8 ed. Rio de Janeiro: Freitas Bastos, 1977, 355 p.

ARAÚJO FILHO, Wilson de. Ordem pública ou ordem unida? Uma análise do curso de formação de soldados da Polícia Militar em composição com a política de segurança pública do Governo do Estado do Rio de Janeiro: possíveis dissonâncias. Rio de Janeiro: EdUFF, 2003, 228 p.

ASHWORTH, Andrew. Principles of Criminal Law. 6 edition. London: Oxford University Press, 2009, $536 \mathrm{p}$.

AURÉLIO, Diogo Pires. Maquiavel e Herdeiros. Lisboa: Círculo de Leitores, 2012, 365 p.

AZEVEDO, Rodrigo Ghiringhelli de. Justiça Penal e Segurança Pública no Brasil: causas e consequências da demanda punitiva. Revista Brasileira de Segurança Pública. a. 3, Ed. 4 fev./mar 2009. Disponível em: < http://revista.forumseguranca.org.br/index.php/rbsp/article/viewFile/42/40>. Acesso em 02 de setembro de 2017.

BARATTA, Alessandro. Criminologia Crítica e Crítica ao Direito Penal: introdução à sociologia do Direito Penal. Tradução Juarez Cirino dos Santos. 3. ed. Rio de Janeiro: Editora Revan: Instituto Carioca de Criminologia, 2002. 254 p.

BBC. 4 explicações para a impressionante queda da violência em Nova York. Disponível em: https://g1.globo.com/mundo/noticia/4-explicacoes-para-a-impressionante-queda-da-violencia-emnova-york.ghtml. Acesso em 24/01/2018.

BECHARA, Ana Elisa Liberatore Silva. Discursos de emergência e política criminal: o futuro do direito penal brasileiro. Revista da Faculdade de Direito da Universidade de São Paulo. v. 103, 2008. Disponível em:< http://www.revistas.usp.br/rfdusp/article/view/67812/70420>. Acesso em 4 de setembro de 2017.

BECCARIA, Cesare. Dos delitos e das penas. Coleção obra-prima de cada autor. São Paulo: Martin Claret. 2014.

BENEVIDES, M. V. Linchamentos: violência e justiça popular. Espaço \& Debates, v. 11, p. 55-90, 1981.

BRASIL. Constituição (1988). Constituição da República Federativa do Brasil. Brasília, DF: Senado Federal. Centro Gráfico, 2014.

Congresso Nacional. Câmara dos Deputados. Comissão Parlamentar de Inquérito do Sistema Carcerário. Relatório Final. Agosto de 2015. Disponível em: <http://www.camara.gov.br/proposicoesWeb/prop_mostrarintegra;jsessionid=B3DF61CB5BA8CBD57 2D116DC0E084F34. proposicoesWeb2?codteor $=1366810$ \&filename $=R E L+2 / 2015+C P I C A R C E+\% 3 D$ $\% 3 \mathrm{E}+\mathrm{RCP}+6 / 2015>$. Acesso em 22 setembro de 2017

Ministério da Justiça. Anuário brasileiro de segurança pública. São Paulo, SP: FBSP, 2016.2 Ano 10.2 Disponível em:<http://www.forumseguranca.org.br/files/files/destaques_anuario2013.pdf>. Acesso em 14 setembro de 2017 
CALDEIRA, César. Política de segurança pública no Rio: apresentação de um debate público. In: ARCHÉ interdisciplinar. Faculdades Integradas Cândido Mendes. Ano VII, N. 19, Rio de Janeiro, 1998.

CERQUEIRA, Daniel et all. Atlas da Violência no Brasil. Rio de Janeiro: IPEA, (2017).

CLEMENTE, Pedro José Lopes. Cidadania, Polícia e Segurança. Lisboa: ISCPSI, 2015, 113 p.

CUNHA, Alexandre dos Santos et. al. Judiciário, reformas e cidadania no Brasil. In.: Estado, instituições e democracia: república. Brasília: IPEA, 2010.

DALARI, Dalmo de Abreu. Elementos da teoria geral do Estado. São Paulo: Saraiva, 1998.

agosto de 2006.

Imprensa livre e responsável. Jornal do Brasil, Rio de Janeiro, 19 de

DIAS, Jorge de Figueiredo. ANDRADE, Manuel da Costa. Criminologia - O homem delinquente e a sociedade criminógena. $2^{\underline{a}}$ reimpressão. Coimbra: Coimbra Editora, 1997.

DZIMIDAS, Carolina Haber. A relação entre o direito e a política no processo legislativo penal. 2012. Tese (Doutorado em Direito) - Faculdade de Direito. Universidade de São Paulo. Disponível em: $<$ http://www.teses.usp.br/teses/disponiveis/2/2139/tde-24042012-114628/pt-br.php>. Acesso em 15 de outubro de 2017.

ELIAS, Luís Manoel André. Dimensões securitárias na contemporaneidade. Lisboa: ISCPSI, 2014, 31 p.

FERNANDES, José Joaquim Antunes. Os desafios da segurança contemporânea. Estado, identidade e Multiculturalismo. Lisboa: Edição do autor, 2014, 133 p.

FERRAJOLI, Luigi. O Direito como sistema de garantias. In: OLIVEIRA JÚNIOR, José Alcebíades de. O novo em Direito e Política. Porto Alegre: Livraria do Advogado, 1997. p. 95.

A pena em uma sociedade democrática. Discursos sediciosos. Crime, direito e sociedade. Rio de Janeiro, ano 7, n. 12, p. 37, 2‥ Semestre de 2002a.

. Direito e razão. Teoria do garantismo penal. Tradução de Ana Paula Zomer et al. São Paulo: Revista dos Tribunais, 2002b.

FISCHER, Douglas. O que é garantismo penal (integral)? In: CALABRICH, B. et al. Garantismo penal integral - Questões penais e processuais, criminalidade moderna e aplicação do modelo garantista no Brasil. Salvador: Jus Podivm. 2010.

. Garantismo penal integral = direito adequado à defesa e não a um defensivismo Nacional do Ministério Público. 2013. Disponível em:< http://www.gnmp.com.br/publicacao/218/garantismo-penal-integral-direito-adequado-a-defesa-e-naoa-um-defensivismo-diet>. Acesso em 05 de novembro de 2017.

GARCIA-PABLOS DE MOLINA, Antonio. Criminologia: introdução a seus fundamentos teóricos. São Paulo: Editora Revista dos Tribunais, 1997.

GUIMARÃES, Cláudio Alberto Gabriel. A dogmática jurídico-penal em questão: possibilidades e limites no século XXI. Espaço Jurídico: Journal of Law. Santa Catarina. Editora Unoesc. v.8, n.2 2007. Disponível em: <http://editora.unoesc.edu.br/index.php/espacojuridico/article/view/1895/963>.Acesso em 21 de dezembro de 2017.

. Constituição, Ministério Público e Direito Penal. A defesa do estado democrático de direito no âmbito punitivo. São Paulo: Revan. 2010.

Reflexões acerca do controle social formal: rediscutindo os fundamentos do direito de punir. Revista da faculdade de direito da UERJ-RFD. Rio de Janeiro, v.1, n.23, 2013. Disponível em: <http://www.e-publicacoes.uerj.br/index.php/rfduerj/article/view/4894. Acesso em 21 de julho de 2017. 
; PEREIRA, Paulo Fernando Soares. Reflexões a respeito da necessidade de participação dos Municípios na formulação e implementação de políticas de segurança pública. Revista Quaestio luris, vol. 07, №. 02, Rio de Janeiro, 2014. p. 812-839.

HELLER, Hermann. Teoria do Estado. Tradução de Lycurgo Gomes da Mota. São Paulo: Mestre Jou, $1968,374 \mathrm{p}$.

HOBBES, Thomas. Leviatã. Coleção obra-prima de cada autor São Paulo: Martin Claret. 2014.

IPEA Instituto de Pesquisa Econômica e aplicada. Relatório final de Pesquisa. Reincidência Criminal no Brasil. $2015 \quad$ Disponível em:< http://www.cnj.jus.br/files/conteudo/destaques/arquivo/2015/07/9273eaea20159abdadb8bb43a3530f4 9.pdf>. Acesso em 12 de novembro de 2017.

KATZ. Jack. What makes crimes news? In: NEWBURN, Tim. (Org.) Key readings in criminology. London: Willan Publishing, 2009, p. 68-70.

LIMA, Renato Sérgio et el. Estado, polícias e Segurança Pública no Brasil. Revista de Direito da Fundação Getúlio Vargas. N.1, V. 12, São Paulo, 2016.

LOMBROSO, César. O homem delinqüente. Tradução, atualização, notas e comentários de Maristela Bleggi Tomasini e Oscar Antonio Corbo Garcia. Porto Alegre: Ricardo Lenz Editor, 2001, 560 p.

LOCKE, John. Segundo tratado sobre o governo civil e outros escritos. Tradução de Magda Lopes e Marisa Lobo da Costa. Petrópolis: Vozes, 1994.

LUIZ, Ronilson de Souza. Ensino Policial Militar: necessidades, práticas e a matriz curricular nacional. 2008 Disponível em:< http://www.observatoriodeseguranca.org/files/TESE\%20pre-textuais.pdf>. Acesso em 10 de fev. 2015.

MANTOVANI, Fernando. El siglo XIX y las Ciencias Criminales. Santa Fé de Bogotá: THEMIS, 2000, $69 \mathrm{p}$.

MARTINS, José de Sousa. Linchamentos - A justiça popular no Brasil. São Paulo: Contexto, 2015.

As condições do estudo sociológico dos linchamentos no Brasil. Revista de Estudos Avançados, N. 9. V. 25, 1995, p. 295-310.

MASI, Carlo Velho. A crise de legitimidade do Direito Penal na sociedade contemporânea. Rio de Janeiro: Lumen Juris, 2014, 303 p.

MORAN, Michel, REIN, Martin, GOODIN, Robert F. The Oxford Handbook of Public Policy. Oxford: Oxford University Press, 2015, 983 p.

MUÑOZ CONDE, Francisco. Direito penal e controle social. Tradução de Cintia Toledo Miranda Chaves. Rio de Janeiro: Forense, 2005, $116 \mathrm{p}$.

NEWBURN, Tim. Criminology. Devon: Willan Publishing, 2009, 1019 p.

OLIVEIRA, José Pereira de. A manutenção da ordem pública em democracia. Lisboa: ISCPSI, 2015, $516 \mathrm{p}$.

O'MALLEY, Pat. Risk, power and crime prevention. In: NEWBURN, Tim. (Org.) Key readings in criminology. London: Willan Publishing, 2009, p. 373-378.

OLMO, Rosa del (Org.). America Latina y su Criminología. 2. ed. Buenos Aires: Siglo Veintiuno, 1984, $272 \mathrm{p}$.

ROCK, Paul. Sociological Theories of crime. The Oxford Handbook of Criminology. Oxford: Oxford University Press, 2007, p. 3-23. 
ROUSSEAU, Jean-Jacques. Do contrato social. São Paulo: Martin Claret, 2013.

SANTIN, Valter Foleto. A participação do Ministério Público e do cidadão na política de segurança pública. Revista Justitia. n. 63, 2001. Disponível em:< http://www.revistajustitia.com.br/revistas/x86w33.pdf >. Acesso em 07 de setembro de 2017.

SANTOS, Juarez Cirino. A Criminologia radical. Curitiba: IPCP: Lumen Juris, 2006.

SAPORI. Flávio. Prisões e impunidade. Carta Capital. 2011. Disponível em: <http://www.cartacapital.com.br/politica/prisoes-e-impunidade>. Acesso em 23 de setembro de 2017.

SENTO-SÉ. João Trajano. (Org.) Prevenção da violência. O papel das cidades. Rio de Janeiro: Civilização Brasileira, 2005.

SILVA, Rosimeri Aquino; TASCHETTO, Leônidas Roberto. Direitos humanos e polícia. Civitas. Porto alegre. v.8, n.3.

SILVESTRE, Juliana Queiroz. A legitimidade do direito de punir em decorrência do não cumprimento de obrigações constitucionais pelo Estado. 2008. Dissertação (Mestrado em Direito) - Faculdade de História Direito e Serviço social. Universidade Estadual Paulista "Júlio de Mesquita Filho". Franca, 2008.

SOARES, Luis Eduardo. Segurança municipal no Brasil - sugestões para uma agenda mínima. In: SENTO-SÉ. João Trajano. (Org.) Prevenção da violência. O papel das cidades. Rio de Janeiro: Civilização Brasileira, 2005. p. 15-44.

Novas políticas de segurança pública. Revista de Estudos Avançados, vol.

17, N. 47, São Paulo, Jan./Apr. 2003.

STREIT, Maíra. Linchamentos no Brasil e a naturalização da barbárie. Revista Forum. Disponível em: https://www.revistaforum.com.br/2015/07/20/semanal-linchamentos-no-brasil-e-a-naturalizacao-dabarbarie/ Acesso em 24/01/2018.

TAQUARY, Eneida Orbage de Britto. A formação do sistema penal brasileiro. Revista Universitas Jus. Brasília, $\quad$ v. 17, jul./dez. $2008 . \quad$ Disponível <http://www.publicacoesacademicas.uniceub.br/index.php/jus/article/viewFile/635/551>. Acesso em 10 de agosto de 2017.

VALENTE, Manoel Monteiro Guedes. Segurança um tópico Jurídico em reconstrução. Lisboa: Âncora Editora, 2013, 146 p.

$2015,145 p$

A Polícia do Estado Democrático de Direito. Florianópolis: Empório do Direito,

WAISELFISZ, J.J. Mapa da Violência 2016: Homicídios por armas de fogo no Brasil. Rio de Janeiro: FLACSO, 2016.

WELSH, Brandon C., FARRINGTON, Davia P. The Oxford Handbook of Crime Prevention. Oxford: Oxford University Press, 2016, 543 p.

WEBER, Rachel, CRANE, Randall. The Oxford Handbook of Urban Planning. Oxford: Oxford University Press, 2015, 864 p.

WILSON, James Q., KELLING, George L. Broken Windows. In: NEWBURN, Tim. (Org.) Key readings in criminology. London: Willan Publishing, 2009, p. 295-300.

WHITE, Rob, HAINES, Fiona, ASQUITH, Nicole. Crime and Criminology. London: Oxford Press, 2012, $333 \mathrm{p}$.

ZAFFARONI, Eugenio Raul, et al. Direito Penal brasileiro. Teoria geral do Direito Penal. Rio de Janeiro: Revan, 2003, 658 p. 
; PIERANGELI, José Henrique. Manual de Direito Penal Brasileiro: parte geral. 3 ed. São Paulo: RT, 2011, 888 p.

\section{COMO CITAR ESSE DOCUMENTO:}

GABRIEL GUIMARÃES, Claudio Alberto. Violência e controle social formal: reflexões sobre o sistema penal no estado democrático de direito. Revista do Direito, Santa Cruz do Sul, v. 1, n. 57, jul. 2019. ISSN 1982-9957.

Disponível

em:

$<$ https://online.unisc.br/seer/index.php/direito/article/view/11863>. Acesso em: doi:https://doi.org/10.17058/rdunisc.v1i57.11863. 